Vol. LXVI 2015

\title{
CNC MACHINING OF THE COMPLEX COPPER ELECTRODES
}

\author{
POPAN Ioan Alexandru \\ Faculty of Machine Building/Department of Manufacturing Engineering, "Technical University of Cluj- \\ Napoca", Romania, ioan.popan@tcm.utcluj.ro \\ BALC Nicolae \\ Faculty of Machine Building/Department of Manufacturing Engineering, "Technical University of Cluj- \\ Napoca", Romania, nicolae.balc@tcm.utcluj.ro \\ POPAN Alina \\ Faculty of Machine Building/Department of Manufacturing Engineering, "Technical University of Cluj- \\ Napoca", Romania, ioan.popan@tcm.utcluj.ro
}

Abstract: This paper presents the machining process of the complex copper electrodes. Machining of the complex shapes in copper is difficult because this material is soft and sticky. This research presents the main steps for processing those copper electrodes at a high dimensional accuracy and a good surface quality. Special tooling solutions are required for this machining process and optimal process parameters have been found for the accurate CNC equipment, using smart CAD/CAM software.

Key words: CAD/CAM, CNC machining, 3D complex copper electrodes

\section{Introduction}

CNC milling technology is one of the most important methods used in industry to manufacture different materials. CNC milling is proving to be productive and flexible for manufacturing complex 3D shapes [1, 2]. It has various distinct advantages over the other cutting technologies, such as: high machining versatility, high flexibility and has been proven to be an effective technology for processing various engineering materials $[3,4]$.

Current trends in the manufacturing industry require that parts must be manufacture in a short time, at a good surface quality, high dimensional accuracy and complex 3D shapes. To manufacture complex 3D parts is important to use CAD/CAM software $[5,6,8]$. This type of software is having various strategies for processing complex 3D shapes with fine details [9, 11, 12].

\section{3D modelling of the electrodes}

In this study the 3D model presented in figure 1 has been used. This 3D model represents a copper electrode, designed for processing a complex mould.
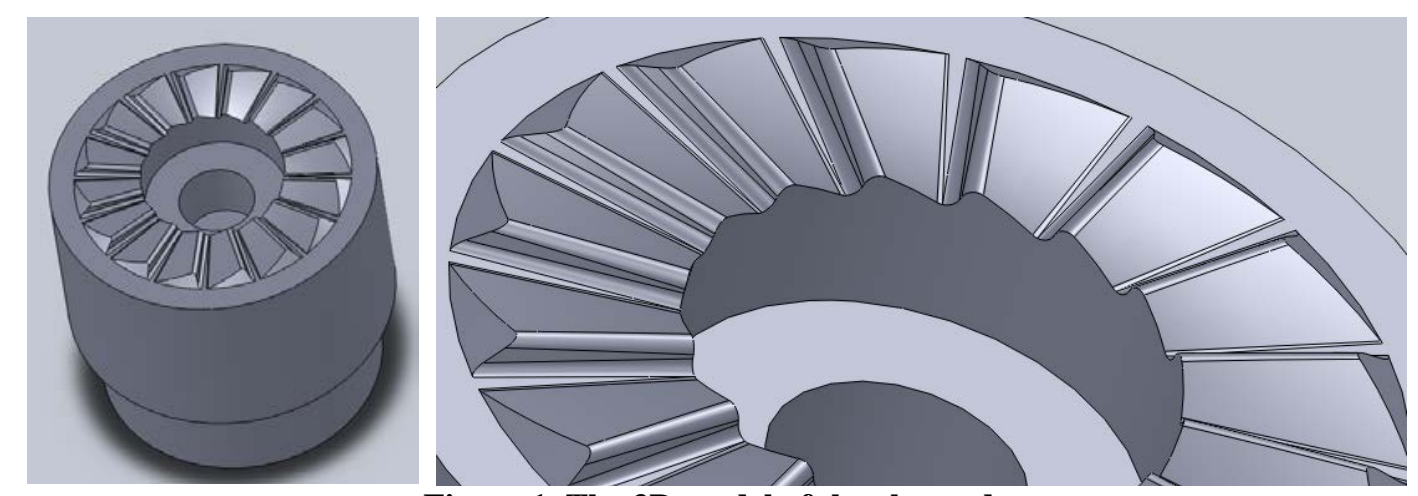

Figure 1. The 3D model of the electrode 


\section{Tooling solutions and process parameters}

It is difficult to manufacture cooper alloys parts by using normal tools, because this type of material is very sticky. For process this cooper electrode was chosen a special type of end mill made by Mitsubishi. The end mills are made from carbide, with 2 flutes at $30^{\circ}$ and CRN coating.

For roughing operation was selected an end mill, with code CRN2MB, as presented in figure 2.

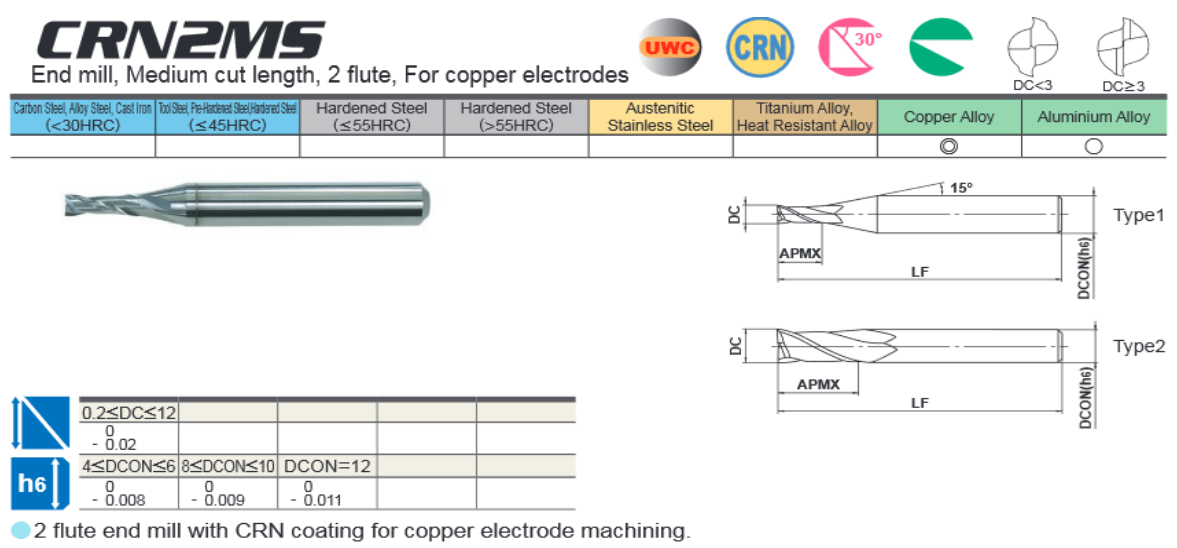

Figure 2: The tools for roughing operation [10]

The process parameters for roughing operation are:

- $\quad$ End mill 12mm, code: CRN2MSD1200S12:

o Rotation speed: 5400 [RPM]; Feed Rate: 820 [mm/min];

0 Depth of processing: $A p=1[\mathrm{~mm}]$; Width of processing: $\mathrm{Ae}=12[\mathrm{~mm}]$.

- $\quad$ End mill 2mm, code: CRN2MSD0200S06 :

o Rotation speed: 11000 [RPM]; Feed Rate: 300 [mm/min];

o Depth of processing: Ap=0.18[mm]; Width of processing: $\mathrm{Ae}=2[\mathrm{~mm}]$.

For finishing operations was chosen a ball mill with code CRN2MB, as in figure 3.
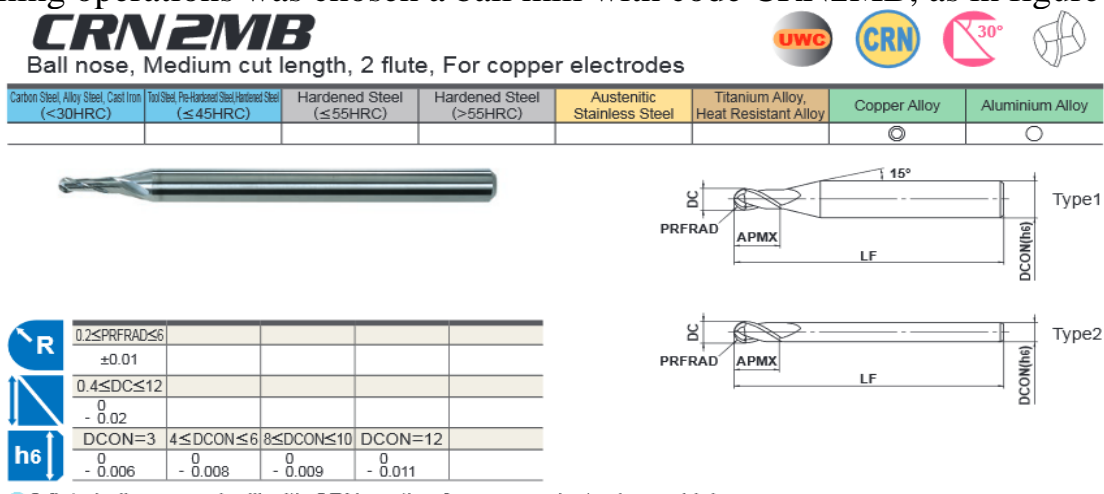

Figure 3: The tool for finishing operation [10]

The process parameters for finishing operation are: Ball mill 1[mm], code: CRN2MBR0100S06; Rotation speed: 11000 [RPM]; Feed Rate: 1000 [mm/min]; Depth of processing: Ap=0.11[mm];

The width of processing $[\mathrm{Ae}]$ is a very important parameter in finishing of $3 \mathrm{D}$ complex surfaces. It has a direct influence on the surface quality. For calculating this parameter, the next formula could be used.

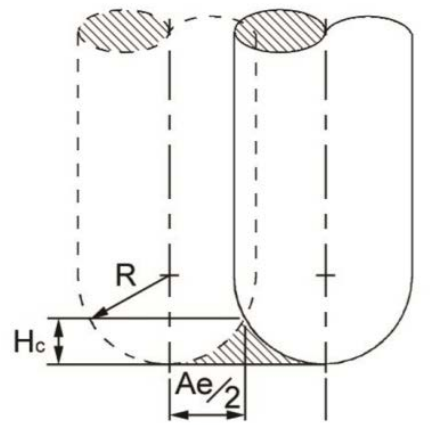

$$
\begin{aligned}
& H c=R-\sqrt{R^{2}-\left(\frac{A e}{2}\right)^{2}} \\
& A e=2 \sqrt{R^{2}-(R-H c)^{2}}
\end{aligned}
$$

Figure 4: The width of processing [Ae] [7] 
In formula (1) exists a parameter Hc, which represents the height of surface roughness. For converting $\mathrm{Hc}[\mu \mathrm{m}]$ in a general parameter for surface quality Ra $[\mu \mathrm{m}]$ can be use the Table 1 [7].

Table 1: Roughness parameters

\begin{tabular}{|c|c|c|c|c|c|c|c|c|}
\hline$H_{C}(\mu \mathrm{m})$ & 0,2 & 0,4 & 0,7 & 1,25 & 2,2 & 4 & 8 & 12,5 \\
\hline $\mathrm{R}_{\mathrm{A}}(\mu \mathrm{m})$ & 0,03 & 0,05 & 0,1 & 0,2 & 0,4 & 0,8 & 1,6 & 3,2 \\
\hline
\end{tabular}

In our study was calculated the width of processing, $A e=0.05 \mathrm{~mm}$.

\section{Computer aided manufacturing}

For manufacturing a complex part (as presented in figure 5) was used a CAD/CAM software applications, SolidWorks and SolidCAM. The first step in this process was the roughing operation. For computer aided manufacturing was started with the defining of the work piece $(1 \mathrm{~mm}$ bigger than the final part) and setting the zero point (was choose in the top and middle of the part), as in figure 5.

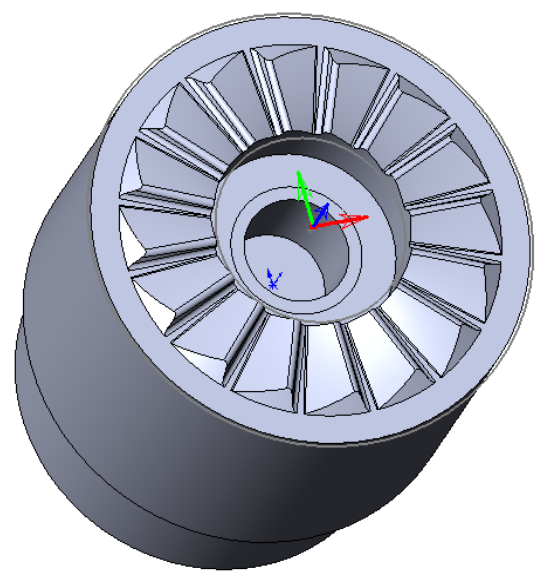

Figure 5: The zero point

The first step in this manufacturing was roughing operation. To obtain a short time for processing from SolidCAM was chose the High Speed Machining application and the Contour Roughing processing strategy. The rouging operation was made in 2 steps. At the beginning was used and end mill of $12 \mathrm{~mm}$ diameter, for quickly remove of material. For completing the roughing operation the Rest Roughing strategy was used and a smaller tool, of $2 \mathrm{~mm}$ diameter (see figure 6). For finishing the 3D surface remained $0.2 \mathrm{~mm}$.
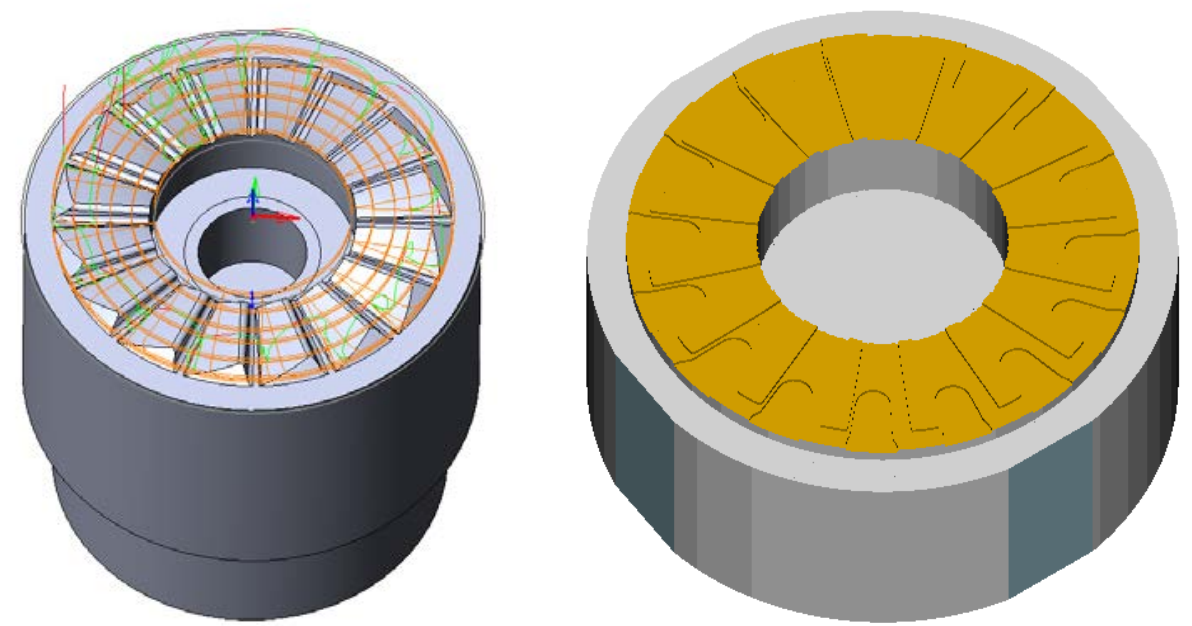

Figure 6: The simulation of the roughing operation

The last operation for manufacturing of the part was the finishing operation. From SolidCAM software was chosen the Constant $Z$ strategy for finishing. Because this strategy could not process very well flat surfaces, was completed with Linear strategy. The distance between two steeps was $0.5 \mathrm{~mm}$. 

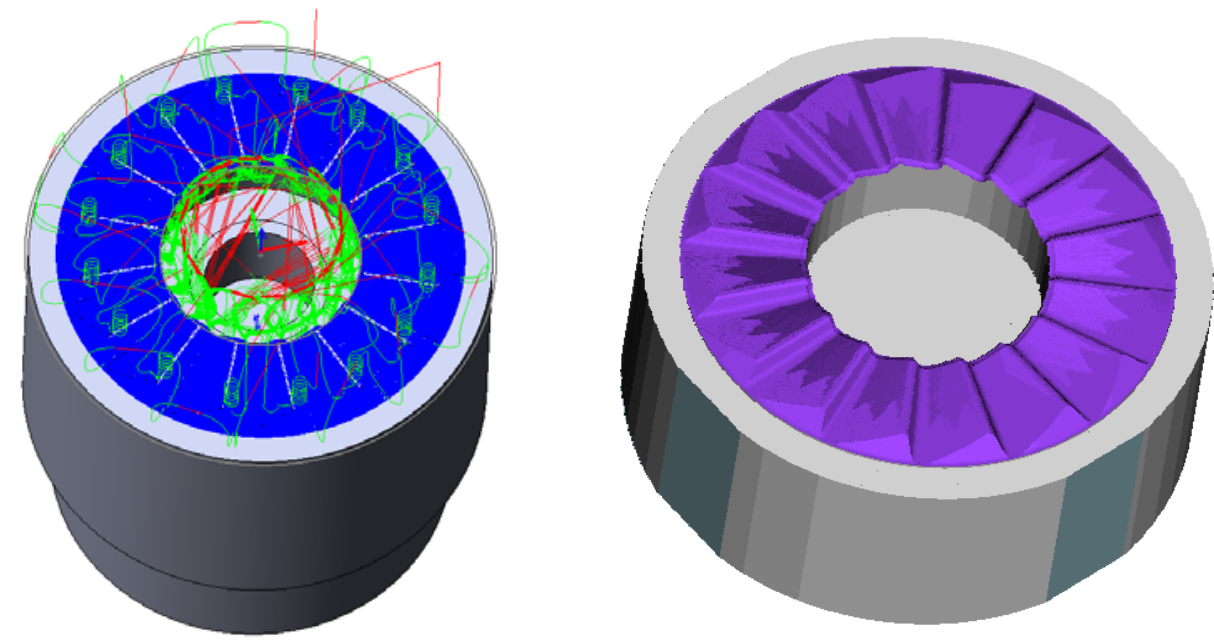

Figure 7: The finishing simulation

To check if the strategy and the distance between steps are well selected was analysed in details the tool trajectory on the graphical simulation.
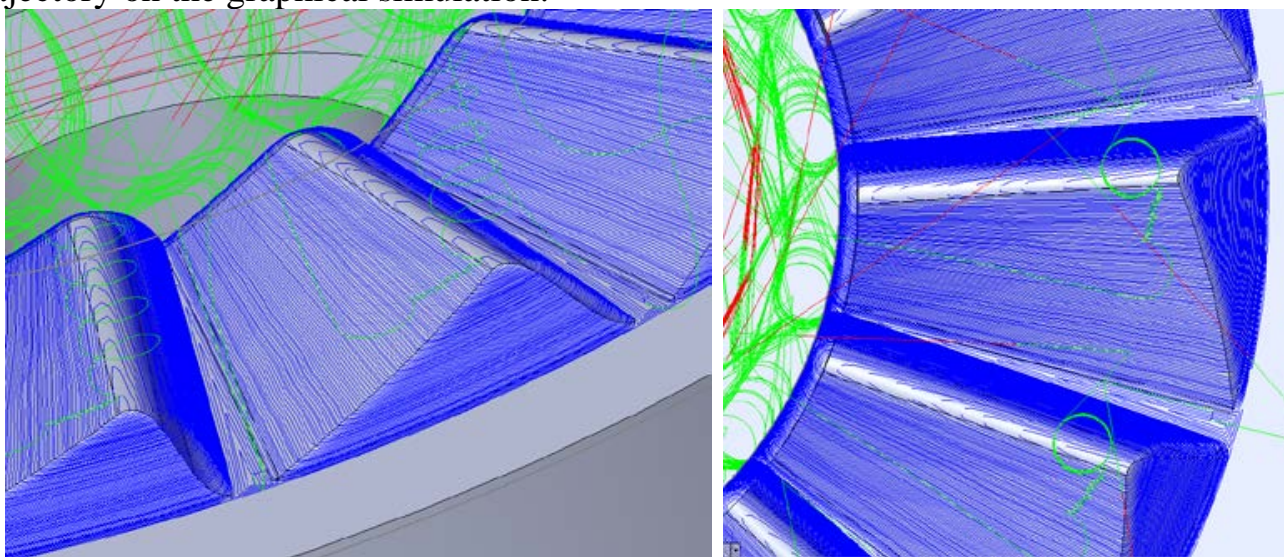

Figure 8: The tool trajectory

For analysing the surface quality was made a 3D simulation, as presented figure 7 and 8 . On this type of simulation we can see exactly the final surface and we can improve it, if it is necessary.

\section{Experimental research}

For this experimental study was selected 3 axis CNC equipment, HAAS VF2, with HAAS controller, from Tehnical University of Cluj-Napoca, Manufacturing Engineering Department (DME). The CNC program, generated by SolidCAM software was loaded on the CNC controller. For fixing the workpiece was manufacture a special clamping device, presented in figure 9 .

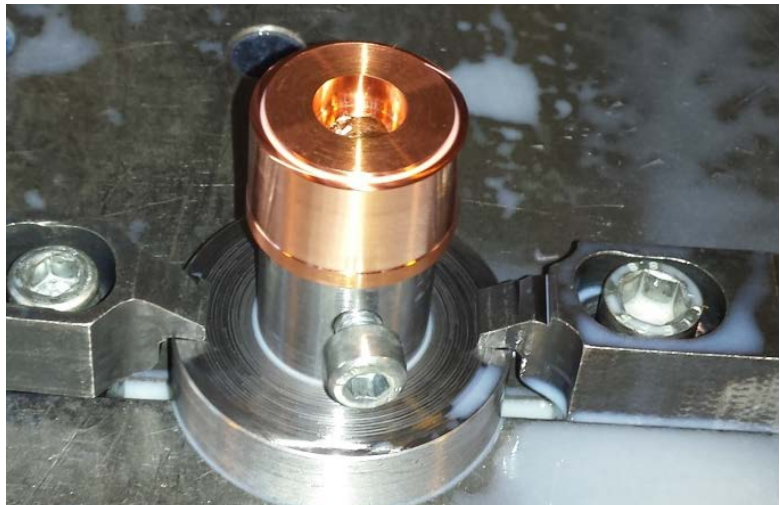

Figure 9: The clamping system

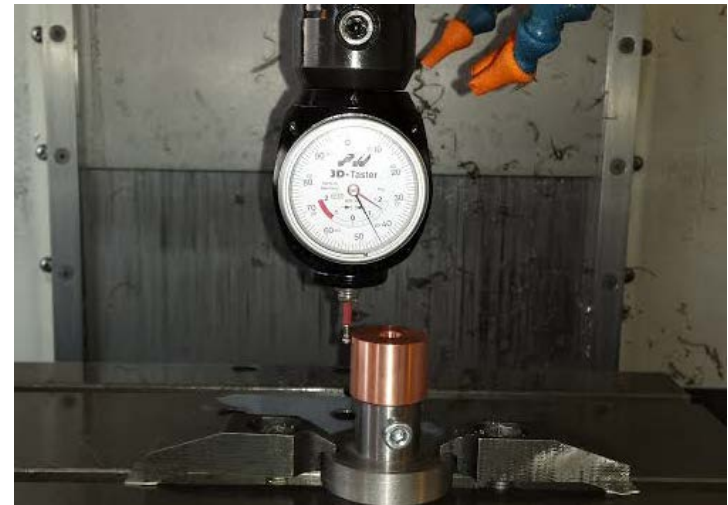

Figure 10: The taking the 0 point 
Using a 3D taster was taken the origin and was measured the cutting tools (see figure 10). The first step in this process is roughing operation. At beginning was used an end mill of $12 \mathrm{~mm}$ diameter for cylindrical and flat milling (figure 11).

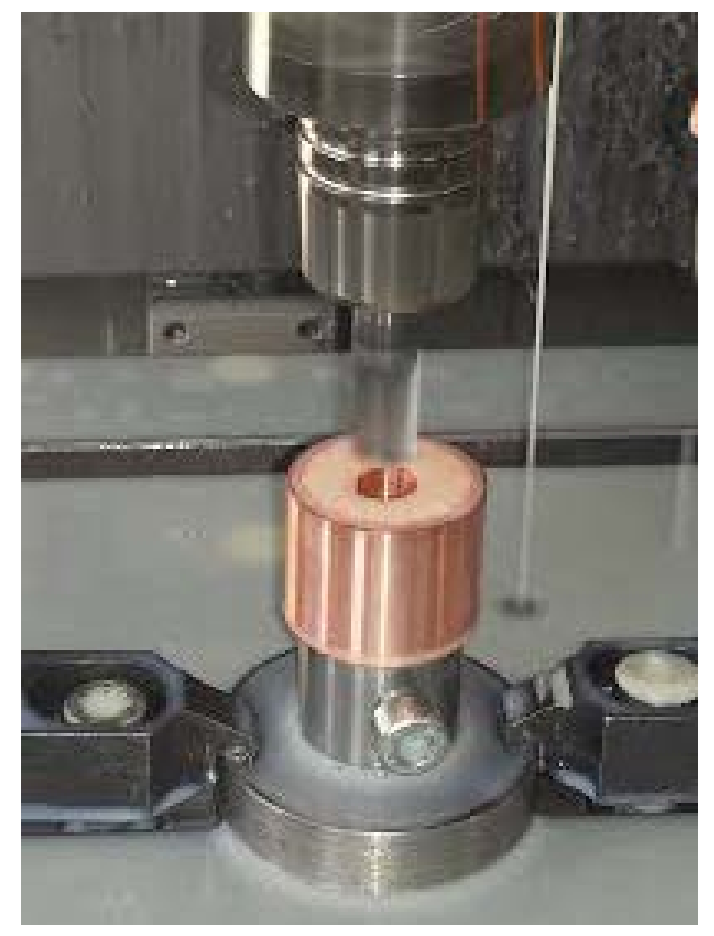

Figure 11: Roughing operation with 12 mm end mill

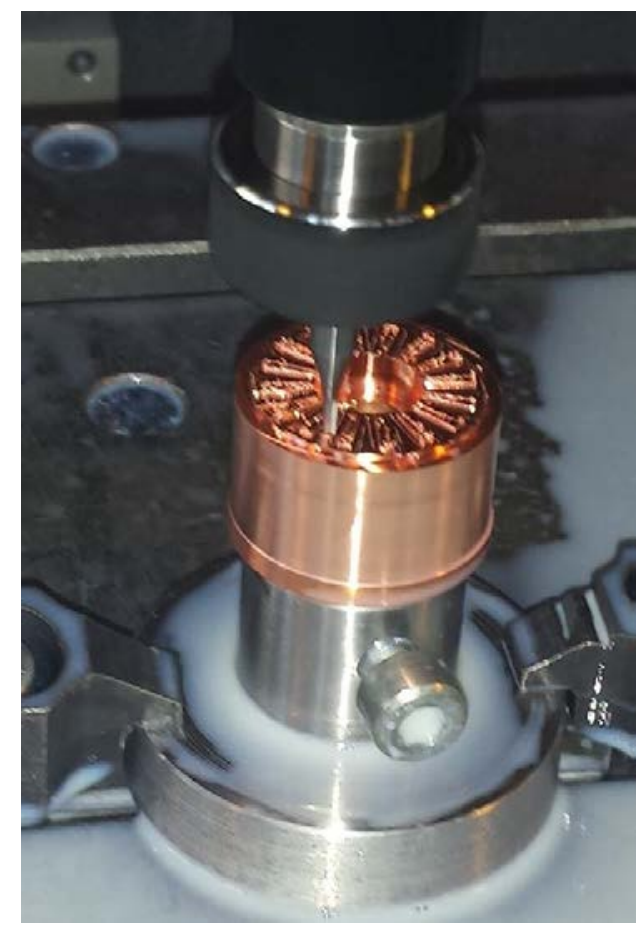

Figure 12: Roughing operation with 2 mm end mill

An end mill with $2 \mathrm{~mm}$ diameter was used for roughing the complex surfaces of the electrode (figure 12). The total time for roughing operation was 0.3 hours. The last part of the process was the finishing operation. For this was used a small ball mill with $1 \mathrm{~mm}$ diameter, because in 3D model exist radius of $0.5 \mathrm{~mm}$ (figure 13 ).

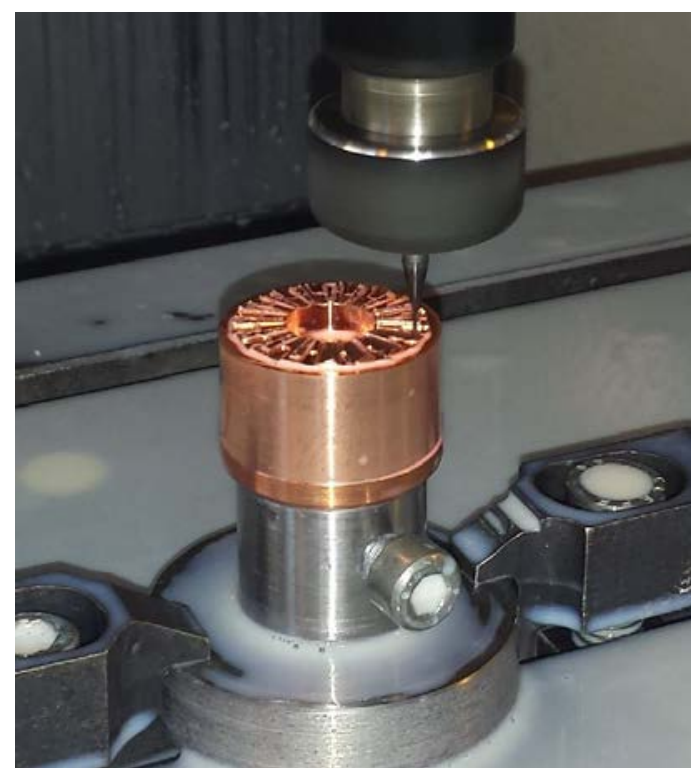

Figure 13: Roughing operation with 2 mm end mill

The total time for finishing operation was 5.2 hours.

\section{Dimensional accuracy}

In this process, the copper electrode from figure 14 was manufactured. During the measurements was obtained a good dimensional accuracy (maximum deviation $=0.04 \mathrm{~mm}$ ) and a good surface quality (Ra $\max =0.16 \mu \mathrm{m})$. 

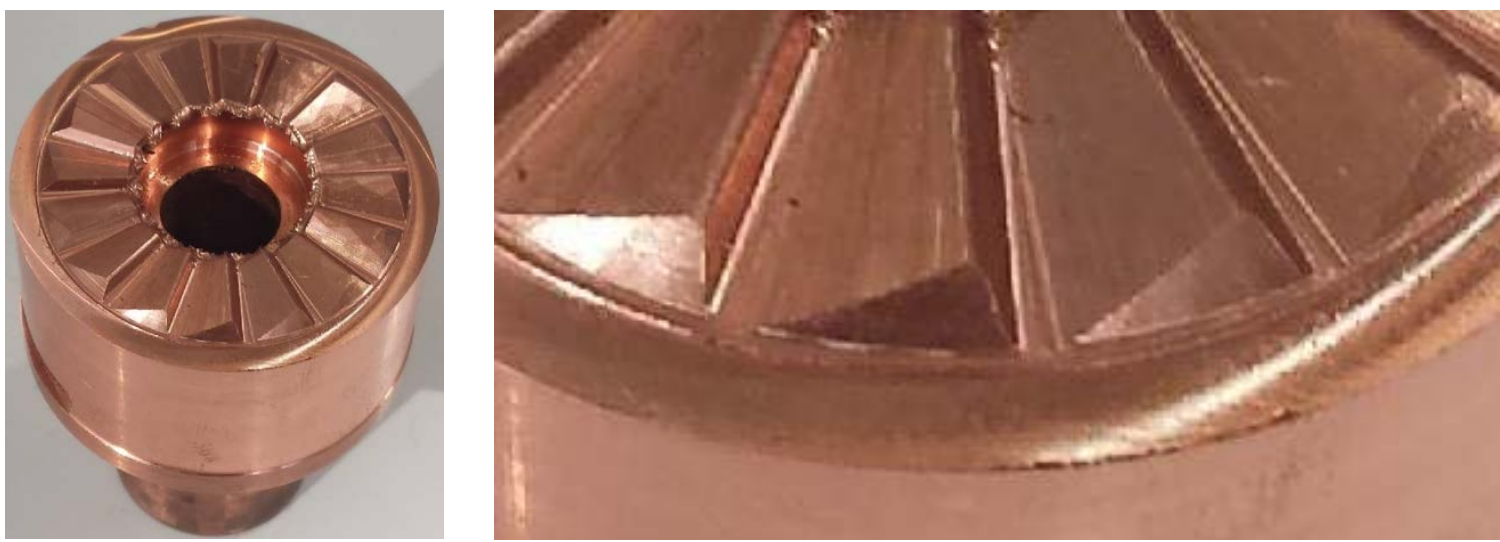

Figure 14: The cooper electrode

\section{Conclusions}

This paper presents an experimental study for manufacturing a complex copper electrode.

To manufacture complex 3D shapes from copper alloy are given the following recommendations:

- $\mathrm{CAD} / \mathrm{CAM}$ software with smart processing strategies;

- Tools solution dedicated for processing coppers;

- The optimal process parameters;

- Faster and precise CNC equipment.

\section{Acknowledgment}

This research has been supported from the project PCCA 115/2014 "PECIFCO”.

\section{References}

- Mohsen Soori, Behrooz Arezoo Mohsen Habibi, Dimensional and geometrical errors of three-axis CNC milling machines in a virtual machining system, Computer-Aided DesignVolume 45, Issue 11, November 2013, Pages 1306-1313.

- Tzeng Yih-Fong, Jean Ming-Der, Dimensional quality optimisation of high-speed CNC milling process with dynamic quality characteristic; Robotics and Computer-Integrated Manufacturing, Volume 21, Issue 6, December 2005, Pages 506-517.

- J. Józwik, I. Kuric, S. D. Grozav, V. A. Ceclan, "R-Test dynamic measurement of 5-axis CNC machining centre rotary axis kinematic centre error" 2014 International Conference on Production Research - Europe, Africa and Middle East, 3rd International Conference on Quality and Innovation in Engineering and Management, pag. 287-292, July 1-5, 2014, Cluj-Napoca, Romania, ISBN: 978-973-662-978-5.

- Chih-Ching Lo, CNC machine tool surface interpolator for ball-end milling of free-form surfaces; International Journal of Machine Tools and Manufacture, Volume 40, Issue 3, February 2000, Pages 307326;

- W.L. Feng, X.D. Yao, Arynov Azamat, J.G. Yang, Straightness error compensation for large CNC gantry type milling centers based on B-spline curves modeling; International Journal of Machine Tools and Manufacture, Volume 88, January 2015, Pages 165-174.

- www.mitsubishi.com

- V. Bulej, J. Uríček, V. Poppeova, R. Zahoranský, M. Rupikova, "Study of the Workspace of Hybrid Mechanism Trivariant", Applied Mechanics and Materials, Vol 436, pp. 366-373, October, 2013.

- www.mstar.ro.

- Ivan Kuric, Matúš Košinár, Miroslav Cisár, Measurement and analysis of CNC machine tool accuracy in different location on work table; Proceedings in Manufacturing Systems, Volume 7, Issue 4, 2012;

- L. Morovič, P. Pokorný, "Optical 3D Scanning of Small Parts", Advanced Materials Research, Vol. 468471, pp. 2269-2273, February, 2012

- www.mitsubishicarbide.com

- Alexandru, Carean; Nicolae, Balc; Razvan, Curta, Researches on machining of complex parts on CNC turning centres with milling capabilities, Academic Journal of Manufacturing Engineering, VOL.7, Issue 3/2009, pg. 78-83, ISSN: 1583-7904.

- G. Królczyk, M. Gajek, S. Legutko, Effect of the cutting parameters impact on tool life in duplex stainless steel turning process, Tehnicki Vjesnik-Technical Gazette 20 (4), 587-592 